\title{
Gambling Disorder and Suicide: An Overview of the Associated Co-Morbidity and Clinical Characteristics
}

\author{
Martinotti Giovanni, ${ }^{1}$ Sarchione Fabiola, ${ }^{1,}{ }^{*}$ Fiori Federica, ${ }^{1}$ Corbo Mariangela, ${ }^{1}$ Poloni Nicola, ${ }^{2}$ \\ Tarricone Ilaria, ${ }^{3}$ Serafini Gianluca, ${ }^{4}$ Pompili Maurizio, ${ }^{5}$ and Di Giannantonio Massimo ${ }^{1}$ \\ ${ }^{1}$ Department of Neuroscience, Imaging and Clinical Sciences, University “G. D'Annunzio”, Chieti, Italy \\ ${ }^{2}$ Department of Clinical and Experimental Medicine, Psychiatric Division, University of Insubria, Varese, Italy \\ ${ }^{3}$ Department of Medical and Surgical Sciences, Bologna University, Bologna, Italy \\ ${ }^{4}$ Department of Neuroscience, Rehabilitation, Ophthalmology, Genetics, Maternal and Child Health, Section of Psychiatry, University of Genoa, Genoa, Italy \\ ${ }^{5}$ Department of Neurosciences, Mental Health and Sensory Organs, Suicide Prevention Center, Sant'Andrea Hospital, Sapienza University of Rome, Rome, Italy \\ "Corresponding author: Sarchione Fabiola, Department of Neuroscience, Imaging and Clinical Sciences, University “G. D’Annunzio”, Chieti, Italy. Tel: +39-0871358931, Fax: \\ +39-0871411570, E-mail: biol4@hotmail.it
}

Received 2015 June 16; Revised 2016 May 23; Accepted 2016 August 21.

\begin{abstract}
Context: A high prevalence of suicide and attempted suicide in relation to gambling disorder is in increasing evidence in current scientific data. The objective of this review was to explore if there was a primary correlation between psychiatric co-morbidities and gambling and/or a secondary correlation with suicide acts.

Evidence Acquisition: We performed a critical analysis of the most recent papers in the scientific literature in this regard and report on the most significant findings.

Results: A direct relationship between gambling and suicidality was highlighted in a number of European, American, and Asian countries. However, it was not clear whether or not gambling increased the risk of suicidal behavior. Two general trends were noted. The first was that gamblers with extreme gambling behavior incurred economic losses and debts to such an extent that suicidal acts appeared to be the only solution. The second was that suicidal acts by gamblers were precipitated by interpersonal and/or working challenges, in conjunction with personality traits of impulsivity and psychiatric co-morbidities.

Conclusions: A combination of impulsivity, certain psychiatric disorders, and social factors may explain the frequent occurrence of suicidal behavior in gamblers.
\end{abstract}

Keywords: Comorbidity, Impulsive Behavior, Pathological, Gambling, Substance-Related Disorders, Suicide

\section{Context}

"Pathological gambling" and "gambling disorder" define a disorder that relates to loss of control over gambling. A gambler is said to be "pathological" when his or her behavior is persistent and reflective of a recurrent maladaptive gambling attitude, or corresponds with five of the 10 diagnostic criteria delineated in the Diagnostic and Statistical Manual of Mental Disorders, Forth Edition (DSM-IV), where it is defined as an "Impulse Control Disorder" (1).

The definition of "pathological gambling" in the DSM$I V$ was replaced with "gambling disorder" in the DSM-5 and differs in that is includes four rather than five diagnostic criteria. (The "illegal acts" criterion is excluded from the most current edition) (2).

Gambling disorder occurs in approximately $0.2 \%-2.0 \%$ of adults, and impacts upon family members, employers and society as a whole (3). The prevalence of gambling disorder in Europe was estimated to be $0.8 \%$ and $74.0 \%$ in Switzerland (4) and Sweden, respectively (5). A gambling commission has been established in England to monitor gambling prevalence and its associated risk factors. Gambling prevalence was reported to be $46 \%$ in men and $54 \%$ in women following the 2010 British Gambling Prevalence Survey (6). Enhanced gambling symptoms were observed in gamblers from an immigrant background in a German study (7). A gambling disorder prevalence of $7.0 \%$ was recorded, with a greater involvement of men, in a study conducted in Italy in 2011 on addictive behavior in adolescents (8).

It has been argued that different ethnic and racial groups influence the prevalence of gambling disorder, but not its onset, course, or symptoms. Differences mainly relate to cultural perceptions of gambling and its acceptability within society and it does seem to be linked with suicidality too. In this respect, Japan is a paradigmatic example. The Japanese are anxious to conceal undesirable gambling habits from other people. Exposure in this regard results in disastrous consequences. If a gambler's name is published in a local newspaper or if the subject is found guilty of a gambling offence, the social stigmatization, humilia- 
tion and social exclusion is so entrenched that a move to another city where their private information is not known often results (9). Alternatively, gamblers prefer to attempt suicide, rather than face their family's disappointment and humiliation, as well as the risk of being ostracized themselves. Gambling involves different kinds of inducement, including repose, excitation, the ability to socialize, and the stimulation of dispute. It is also a way of escaping from difficult circumstances. Nevertheless, the primary motivation of gamblers seems to be the desire to make significant financial gains and to improve their financial position.

Some studies have been conducted on the specific temperamental features of gamblers. Pathological gamblers were demonstrated to consider novelty seeking and selftranscendence as high incentives and self-directedness and cooperativeness as low incentives in a study by Martinotti et al. on 65 gambling subjects (10). The same was described by Janiri et al. in their study (11).

Unfortunately, only $8 \%$ of gamblers ask for help. Furthermore, those who do seek treatment are often driven to do so by psychological distress, disability, depressive disorder, or behavior that is characterized by addiction. Thus, their psychiatric co-morbidities may be greater than those of gamblers who do not ask for help (12). Pathological gamblers often suffer adverse consequences. Therefore, is it important to be able to identify and develop effective interventions for these subjects. Evidence of high psychiatric co-morbidity rates, particularly with regard to substance and alcohol use disorders, affective disorders, posttraumatic stress disorder (PTSD), and personality disorders have been reported in several studies in which gambling disorder populations were investigated. A high incidence of suicide and suicidal attempts is associated with certain psychiatric disorders.

The aim of this review was to identify a correlation between a gambling disorder, suicide occurrence and psychiatric co-morbidities to provide insight for further studies into this under-researched but rapidly increasing worldwide public health problem. An evaluation of the rates of and correlation between suicidality and psychiatric comorbidities in pathological gamblers is also provided in this paper.

\section{Evidence Acquisition}

PubMed was searched to identify published metaanalyses, reviews, randomized double-blind trials, openlabel trials, and case reports written in English that focused on a correlation between gambling disorder, suicidality and psychiatric co-morbidities.

Keywords, "gambling" and "suicide" were used. The reference lists of all identified papers were also reviewed.
Papers were included if they had been published in peerreviewed journals.

The search was conducted on 9 October 2015 and yielded 148 results. Seventeen articles were excluded as they were written in languages other than English and 25 articles were excluded for being too dated. A further 20 articles were not included based on their titles and abstracts, as were papers in which a correlation between gambling and suicide was only evaluated in a marginal way or in which the same information was repeated. There was a focus on articles in which correlation was considered to be a key or central topic, including case studies and those with the most relevant results.

A qualitative synthesis of the most representative data is included in this overview following an analysis of the full text of the remaining 86 papers.

Scopus, Google Scholar, and PsychInfo were also searched using the same keywords to identify any studies that might have been missed in the previous analysis. None were found.

\section{Results}

\subsection{Gambling Disorder and Suicidality}

A positive relationship between gambling and suicidality has been found in a number of previous studies (13), but the results were equivocal. It is not possible to establish whether or not gambling is and how it might be responsible for individual suicide (14). It is thought that the rates of suicide attempts and suicide are higher in pathological gamblers than that for the general population, as evidenced in research. Studies have focused mainly on gamblers seeking rehabilitation, who expressed suicidal thoughts or admitted to having attempted suicide previously (15).

It has also been observed that pathological gamblers with suicidal thoughts, compared to other problem gamblers, reported challenges with alcohol or drug abuse, mental health, finances and relationships. The extent to which suicide ideation or attempts can be linked to gambling, as opposed to other factors, has not been established. The use of different population samples has resulted in ambiguous findings (16).

Moran at al. (17) conducted a study on 162 gamblers registered with Gamblers Anonymous (GA). They found that $20 \%$ of the subjects had attempted suicide and $77 \%$ had suicidal thoughts. One hundred and sixty-four GA members were included in a subsequent study by Frank et al. (18). The results suggest that $13 \%$ of the population reported a history of suicide attempts and $48 \%$ of the population only suicidal ideation. Pathological gamblers who 
sought professional outpatient treatment were evaluated in other studies in the literature. These results showed that $35 \%-42 \%$ of the subjects contemplated suicide and $22 \%$ $31 \%$ reported a suicide attempt (19-21). Of 50 pathological male gamblers in an inpatient unit, $80 \%$ reported suicidal ideation and $12 \%$ attempted suicide (22).

It was highlighted in a literature review by Specker et al. (23) that $12 \%-24 \%$ of suicide attempt rates were attributed to pathological gamblers (24).

Attention is increasingly being given to gambling in recent years. Initial studies were limited by small sample numbers, resulting in newer studies being conducting on larger population samples.

It was shown in a Canadian study, the first survey to be nationally representative of the general population conducted to date, that the association between gambling disorder and attempted suicide in the past year has been significant (25). Gambling disorder was associated with attempted suicide in the final logistic regression model, which included gambling disorder, major depression, alcohol dependence, and mental health care, as well as age, sex, education, and income, but it was not possible to establish whether or not the relation was causal.

Moghaddam et al. analyzed five gambling groups derived using the DSM-IV criteria for pathological gambling and involving 13578 individuals who participated in the National Epidemiologic Survey on alcohol and related conditions in a Californian study (26). Pathological gambling was associated with suicidal ideation and suicide attempts after adjusting for sociodemographic variables. Thon et al. found that a suicide attempt history could be attributed to $10 \%$ of pathological gamblers in a nationwide Austrian treatment population sample (27).

Many studies have attempted to find a possible link between the presence of casinos and the rate of completed suicides. The results remain controversial. The highest rates of completed suicides have been observed in cities where there are numerous opportunities for gambling. However, it has also been noted that there is not a corresponding increase in the number of suicides in cities in which new casinos have opened (28).

Séguin et al. investigated two groups of individuals who had completed suicide, one with and the other without gambling problems (29). The findings showed that the two groups were comparable in terms of psychopathology, with the exception of those with cluster B personality disorders and gambling disorder. Although both groups had tended to use mental health services less frequently in the month prior to their suicide than they had done in the previous year, this was more marked in gambling disorder with suicide.

The study by Bischof et al. was the first to analyze the role of personality disorders in suicidal behavior among pathological gamblers (30). The results emphasized that cluster B personality disorders in which impulsivity featured strongly were especially prognostic of, and were a serious risk factor for, a suicidal event.

Petry et al. conducted a study on individuals who sought help for pathological gambling. They divided the participants into three groups based on their history of lifetime suicidality, categorized as those who had been involved in a suicidal attempt, those with the absence of suicidal thoughts, and those with suicidal ideation alone. Pathological gamblers with a previous history of suicidality reported the presence of psychiatric disturbances and more difficulties in their interpersonal relationships than those who were comparatively more emotionally stable. Most of the individuals in this group were single or unsatisfied with their marital and living arrangements. Some of the study subjects experienced a period of conflict in the month prior to the suicide attempt. There was no significant difference in age or gender between those who had attempted suicide and the other groups, but the former was found to have a more substantial treatment history for substance use disorders.

Those with suicidal ideation craved gambling intensely, were frequently bankrupt, spent more money in the month prior to the suicide attempt, and had previously undergone gambling treatment. Gamblers who participate in gambling games for which skills and knowledge are required, rather than luck, need to maintain the ability to engage in decision-making. In one study, the rate of mental distress was reported to be lower in such gamblers who were also associated with a lower suicide attempt rate (22). Suicide attempts and bankruptcy can be predicted by a family history of addiction (31).

Maladaptive social and emotional coping skills have been reported in the family members of gamblers with an addiction disorder. Furthermore, these coping strategies often facilitate the development of pathological gambling and result in suicide attempts and/or bankruptcy.

It has been revealed that both male and female gamblers experience depression, but that the rate of suicidal thoughts and attempts is increased in women. By contrast, men with gambling problems are at higher risk of alcohol abuse and inappropriate sexual behavior (32).

Kausch reported an increased risk of suicide in gambling disorder subjects who abused drugs, perhaps as a result of the associated impulsivity (19). The association between substance abuse or alcohol and gambling has been reported extensively in the literature.

It was found in a retrospective study that it was even stronger in the case of addiction to both alcohol and substances. Of the gamblers who reported a history of suicide, 
$73 \%$ of them had a history of substance abuse or addiction. However, it was noted that it was more common to find a history of suicide among the group of abusers than among the non-abusers (33).

Hodgins et al. exposed the difficulty of obtaining clear data on the relationship between gambling and suicide owing to differences in study population samples (15). Additionally, it was difficult to clearly identify co-morbidities owing to the fact that the same criteria were not applied to all of the studies. Hodgins et al. conducted a study on pathological gamblers and tried to explain the link between pathological gamblers and gambling-related suicides using a model in which common factors could be conceptualized. They suggested that certain factors, such as early onset, lack of treatment, substance use, mood disorders, and financial loss, precipitate individuals with gambling disorder and other psychiatric vulnerabilities to suicidal behavior. They considered three subsamples; subjects without suicidal ideation, subjects with a history of suicidal ideation, and those who had attempted suicide. They observed that suicide ideation often preceded the onset of pathological gambling. This confirms that suicidality is closely linked to issues of a psychopathological nature. In addition, a history of suicidal ideation seems to be linked to worsening gambling behavior. It is more probably that those with a history of suicidal ideation will develop mood disorder. It was also found that individuals who reported a suicide attempt at the time of observation had an history of substance abuse or dependence, and that this was not the case in those with a history of suicidal ideation (15).

Wong et al. evaluated a suicide case series in a psychological autopsy study on suicides with gambling disorder (34). Suicide related to pathological gambling in individuals who had unmanageable debts imputable to gambling in four cases. More than half had mood disorders prior to death. Financial difficulties resulting from gambling disorder might play a key role in the exacerbation of depression. Both are major causal risk factors for suicide. Gambling disorder was considered to be modifiable risk factor for suicide (34).

In a time-series analysis of national data, Chen et al. considered a possible association between the number of suicides and the lottery sales volume in a week in Taiwan (35). They found a positive correlation in this regard when the lottery was characterized by higher winnings, a lower probability of winning and a higher outlay. By contrast, a negative correlation was found when the lottery was characterized by lower winnings, a higher probability of winning and a lower outlay. A weekly lottery featuring a higher winning was more publicized but associated with a lower probability of winning and a higher monetary out- lay, and thus loss, leading to the most ruinous financial consequences (35).

A statistically significant odds ratio (OR) of 4.4 was reported with regard to an association between gambling disorder and suicide plans in a study by Park et al. (12) on a randomly chosen Korean population. The presence of other psychiatric disorders which might have been involved in the suicide plans and attempts, such as depression, mood disorder, or substance abuse or dependence, were not taken into account in the analysis. The OR was no longer statistically significant when psychiatric disorders were factored in. It was concluded that gambling disorder is an independent risk factor for suicide (12).

Wong et al. evaluated the adverse consequences of legalized gambling in public health in a study on suicide cases in Hong Kong (13). They included three sample groups; suicides without gambling behavior, suicides with gambling behavior but no gambling-related debt, and suicides with gambling and gambling-related debt. They found that gambling behavior was prevalent among all the suicides, and that suicide in gamblers with gamblingrelated debts differed to that in the others. Suicide in gamblers without related debt was reported in subjects with a history of psychiatric distress. Primarily, they were recreational gamblers and gambling didn't play had a key role in their suicides. A history of psychiatric illness was not associated with those who were indebted because of gambling. Indebtedness was highlighted as an important risk factor for suicide, especially in individuals involved with loan "sharks" or legal financial institutions prior to their deaths. A strong association was also found between a history of alcohol abuse (but not a history of drug abuse) and suicide (13).

The major studies outlined in this paper are detailed in Table 1.

\subsection{Gambling Disorder and Psychiatric Co-Morbidities}

Gambling disorder is frequently found in subjects with substance use problems (37-39). Gamblers report higher gambling activity following the consumption of alcohol or drugs, are more psychosocially dysfunctional than patients with a single disorder (40) and are refractory to rehabilitation (41).

The onset of substance and/or alcohol abuse usually precedes a gambling problem. Alcohol is the most frequent substance used, followed by marijuana and cocaine. The prevalence of co-morbid alcohol abuse or dependence significantly increases by more than threefold. A high prevalence of alcohol use disorders in pathological gamblers, and gambling disorder in individuals with an alcohol use disorder, is well established in the international literature (42). 
Table 1. The characteristics and main findings of studies on a correlation between gambling and suicidality

\begin{tabular}{|c|c|c|c|}
\hline References & Country & Sample Size & Major Findings \\
\hline Moran et al. (17) & & Anonymous gamblers (162) & $\begin{array}{l}\text { The results showed that } 77 \% \text { of the subjects contemplated suicide and } 20 \% \\
\text { had attempted it. }\end{array}$ \\
\hline Frank et al. (18) & & Anonymous gamblers (164) & $\begin{array}{l}\text { The results demonstrated that } 48 \% \text { of the subjects reported suicidal ideation } \\
\text { only, while } 13 \% \text { of them reported in anamnesis suicide attempts. }\end{array}$ \\
\hline Taber et al. (36) & $\begin{array}{l}\text { Spain, } \\
\text { Germany }\end{array}$ & & $\begin{array}{l}\text { It was found that } 35 \%-42 \% \text { of the study participants contemplated suicide } \\
\text { and } 22 \%-31 \% \text { reported a suicidal attempt. }\end{array}$ \\
\hline Petry et al. (22) & & $\begin{array}{l}\text { Male pathological gamblers (50) in an } \\
\text { inpatient unit }\end{array}$ & $\begin{array}{l}\text { Eighty per cent of the subjects reported suicidal ideation and 12\% attempted } \\
\text { suicide. }\end{array}$ \\
\hline Specker et al. (23) & USA & $\begin{array}{l}\text { Outpatient subjects ( } 40 \text { ) in treatment } \\
\text { for gambling and } 64 \text { controls }\end{array}$ & $\begin{array}{l}\text { The prevalence of suicide attempts ranged from } 12 \% \text { - } 24 \% \text { in pathological } \\
\text { gamblers. }\end{array}$ \\
\hline Seguin et al. (29) & & $\begin{array}{l}\text { Pathological gambling suicides ( } 49) \\
\text { and non-pathological gambling } \\
\text { suicides (73) }\end{array}$ & $\begin{array}{l}\text { The two groups were comparable in terms of psychopathology, with the } \\
\text { exception of cluster B personality disorders and gambling disorder. Although } \\
\text { both groups had tended to use mental health services less frequently in the } \\
\text { month prior to their suicide than they had done in the previous year, this was } \\
\text { more noticeable in gambling disorder suicides. }\end{array}$ \\
\hline Petry (22) & & Participants (347) & $\begin{array}{l}\text { Outpatients with anamnestic episodes of suicidality were found to frequently } \\
\text { experience psychiatric challenges and interpersonal distress (mostly } \\
\text { bankruptcy). Pathological gamblers and subjects without anamnestic } \\
\text { suicidal ideation reported spending more on gambling in the month prior to } \\
\text { commencing treatment. They craved gambling and logged high scores using } \\
\text { the South Oaks gambling screen (a screen for compulsive gambling) }\end{array}$ \\
\hline Kausch (19) & USA & Subjects (113) & $\begin{array}{l}\text { The results showed that there was a higher risk of suicide in gambling } \\
\text { disorder subjects involved in drug abuse than in those who did not abuse } \\
\text { drugs, perhaps as a result of the associated impulsivity. }\end{array}$ \\
\hline Hodgins et al. (15) & & $\begin{array}{l}\text { Individuals with gambling problems } \\
\text { (101) }\end{array}$ & $\begin{array}{l}\text { Frequently, pathological gamblers have psychiatric co-morbidities (mostly } \\
\text { mood disorders and/or substance use). It was found that economic } \\
\text { difficulties precipitated suicidal acts. }\end{array}$ \\
\hline Wong et al. (13) & $\begin{array}{l}\text { Hong Kong, } \\
\text { China }\end{array}$ & Suicides (150) and controls (150) & $\begin{array}{l}\text { All subjects who committed suicide had extensive debt secondary to } \\
\text { gambling, and approximately half of them had mood disorders. Economic } \\
\text { difficulties caused by gambling increased depression. Both are major causal } \\
\text { risk factors for suicide. }\end{array}$ \\
\hline Chen et al. (35) & Taiwan & All suicides aged $\geq 15$ years & $\begin{array}{l}\text { There was a positive association between the number of suicides per week } \\
\text { and the lottery sales volume, characterized by higher winnings, a lower } \\
\text { probability of winning and a higher outlay. }\end{array}$ \\
\hline Park et al. (12) & Korea & Participants (6 510) & $\begin{array}{l}\text { A statistically significant odds ratio of } 4.4 \text { was reported for the association } \\
\text { between gambling disorder and suicide plans }\end{array}$ \\
\hline Wong et al. (34) & $\begin{array}{l}\text { Hong Kong, } \\
\text { China }\end{array}$ & Suicides (1201) recorded in Hong Kong & $\begin{array}{l}\text { Gambling behavior was prevalent among suicides. Indebtedness was seen as } \\
\text { a suicidal risk factor. }\end{array}$ \\
\hline $\begin{array}{l}\text { Newman and } \\
\text { Thompson }(25)\end{array}$ & Canada & Subjects (36984) & $\begin{array}{l}\text { The link between gambling disorder and attempted suicide was found to be } \\
\text { significant. }\end{array}$ \\
\hline
\end{tabular}

The connection between gambling disorder and substance abuse can be explained by the addictive, impulsive, and compulsive nature of these disorders. Suicide attempts are frequent in gamblers. Addictive sexual behavior and compulsive shopping are mostly associated with gambling problems in the presence of comorbidities, such as alcohol or drug disorders, rather than in subjects with gambling disorder problems alone (19). Thus, gamblers are susceptible to addictive, compulsive and impulsive behaviors (20). Perhaps this can be attributed to their genetic predisposition, as supported by scientific data. Coping skill deficits in critical domains have also been observed in gamblers (21).

It has been shown in scientific research that it is more likely that similarities in the co-morbidities in alcohol use disorder and gambling disorder will be observed in men than in women, and such co-morbidities are frequently associated with suicide attempts, daily tobacco use, drug use, and substance abuse in general, as well as a family history of alcohol and/or drug problems and legal problems consequent to gambling.

Bipolar disorder (BD) is frequently associated with gambling disorder because it is characterized by a predisposition to suicide behavior and impulsivity $(43,44)$. A bipolar disorder diagnosis and impulsive conduct (such as gambling disorder, alcohol and drug use, and abuse) has been identified in more men than women according to the scientific data (45). Lithium seems to be the only effective treatment for suicide behaviour, impulsivity, and concurrent disorders (46), probably owing its recently established association with better decision-making in remitted bipolar patients (47) 
An interesting similarity in the co-morbidities in gambling and those in PTSD has been identified in the literature. Approximately $15 \%$ of subjects with lifetime GD met the lifetime PTSD criteria too. Thus, there is a high risk that those with an established PTSD diagnosis will become gamblers. Similarly, gambling disorder symptoms can be seen to be predictive of the subsequent onset of PTSD symptoms (3). Common characteristics in patients with both PTSD and gambling diagnosis have been identified, including depression, anxiety, substance abuse symptoms, an avoidant personality style $(36,48)$, earlier age of gambling onset (49), greater lifetime gambling and psychiatric symptom severity, impulsivity (seen as a central trait in all addictive disorders), dissociation (50), greater frequency of suicide attempts $(15,51)$, drug and alcohol dependence (52), and a tendency to avoid responsibility for problems (53).

Ultimately, the core challenge is represented by trauma, which aside from PTSD, has been found to be associated with problem and/or gambling disorder, and consequently with suicidality (54).

Borderline personality disorder is one of the most frequent personality disorders that is characterized by an important sign; the impulsivity that is present in gambling disorder and suicidality. Impulsivity is commonly assessed using the Iowa Gambling Task (IGT) (29), a computerized assessment that assists in the evaluation of decisionmaking mediated by the prefrontal cortex. A characteristic pattern of impaired performance in borderline patients has been demonstrated with the use of the IGT, which is very similar to that identified in gamblers (55).

An association has been made between gambling disorder and both major depression and suicidality, according to the findings of epidemiological studies.

Participation in online pathological gambling, Internet addiction, and offline pathological gambling appears to correlate strongly with depression. Poker players are overrepresented among online gamblers and gambling behavior tends to be more excessive on the Internet. Compared with offline gamblers, online gamblers report involvement in more co-occurring risky behavior, such as alcohol and cannabis use (56).

In addition, gambling disorder is characterized by a variety of severely negative consequences, such as financial debt, difficulties relating to family and society, problems with employment and legality, psychological suffering (57), child neglect, domestic violence, criminal involvement, and juvenile delinquency (12).

The significant incidence of suicidal ideation and suicide attempts in problem gamblers seeking treatment is a clear indication that patients with gambling addiction should be evaluated for suicide risk and deliberate self- harm.

\section{Discussion}

It has been evidenced in this review that gambling disorder is closely linked to economic, working, social, familial, and emotional problems. In addition, it is associated with several co-morbidities, such as mental health issues (mostly mood and substance use disorders). In general, the rate of suicide attempts has been found to be higher in pathological gamblers than that in the general population.

Although it is not clear whether a psychiatric disorder can be anticipated by gambling or ensues from it, it is certainly used as a vehicle from which to escape daily problems. Nevertheless, gambling disorder results in considerable stress, exacerbating feelings of depression or anxiety, with the potential for these to develop into a mood, anxiety, or substance disorder $(3,9,49)$.

Gamblers rarely make use of professional mental health services. Thus, it is difficult to estimate the extent of the problem and it is only when interpersonal, familial, economic, working, and suicidal problems become evident that they are forced to contact specialized services (29).

The presence of co-morbid psychiatric diseases, mostly DSM-IV Axis I disorders (48), greatly contributes to our understanding of why gamblers are pushed into suicidal behavior, as evidenced by impaired functioning (58), reduced quality of life, and specific medical conditions, as well as high rates of stressful life events, including unemployment, divorce, and bankruptcy (59-61).

In our research, we observed a direct association between gambling problems and consequent suicide deeds. Addiction is found in a great number of gambling subjects with psychiatric co-morbidities and the latter could exacerbate the gambling problem primarily and/or the suicide acts, secondarily. Obviously, a psychiatric disease does not always predispose to gambling primarily and to a suicidal deed secondarily. Similarly, a psychiatric disease does not always predispose to a gambling vice or suicide deeds severally. That being said, it can be speculated that there is a way of predicting the chances of suicidality, or of trying to do so, by taking a comprehensive history from the subject and analyzing all of the associated co-morbidity factors.

It has been hypothesized that gamblers who are also alcohol and drug users have insufficient self-control, defined as a pervasive difficulty in exercising, or refusing to exercise, sufficient self-control and frustration tolerance, in order to achieve one's personal goals. Moreover, insufficient self-control is associated with early maladaptive schemas, 
typical of mental health problems, such as depression, eating disorders, PTSD, and personality disorders (62-65). They are described as cognitive domains which establish how people screen, encode, interpret, and respond to environmental stimuli. Early maladaptive disorders develop during childhood, starting as a result of a traumatic or toxic experience, where people respond with different coping behavior, sometimes involving the use of substances or other addictions. They are seen as vulnerable to the development of mental health problems. Early treatment can reduce the consequent development of addictive behavior (66). Furthermore, it is possible to hypothesize that gambling disorder and certain psychiatric diseases, such as substances abuse and suicidality, are different aspects of the same psychopathological mechanism; impulsivity. It is noteworthy that prolonged alcohol intake is responsible for important effects on mood after acute or chronic administration, during withdrawal, and in protracted withdrawal states (67), which amplifies existing risks.

Gamblers are often depressed and without doubt, subjects with a mood disorder are more likely to be at higher suicidal risk than those without a mood disorder. Sometimes, a suicide attempt may be viewed by an individual as being the only way of escaping from a negative situation caused by gambling (for example, substantial economic losses) (68). In other cases, a depressive substrate is not involved, and suicidality connected to substance abuse and/or gambling disorder may only be explained by relating it to a propensity for impulsivity (69).

The absence of premeditation prior to suicide attempt is common in all these situations and as previously mentioned, relates to an inclination to be impulsive (70). More specifically, it has been evidenced in the scientific literature that those who attempt suicide and those with suicidal ideation demonstrate different behavior. They both wish to urgently commit suicide, but poor premeditation is only observed in those who attempt suicide (71).

Another relevant aspect concerns the profile of impulsivity in gamblers. High scores for a lack of perseverance are recorded in subjects with alcohol use disorders, high scores for a lack of premeditation and perseverance in those with tobacco dependence, and the same applies for a lack of premeditation in those with substance use disorders (with the exception of alcohol and tobacco) (72).

To date, there is no universal acknowledged therapy with which to treat gambling disorder. Further studies and evidence in this regard are required. The scientific data indicate that different pharmaceutical classes, such as antidepressants, mood stabilizers, and opiate agonists, can be used for gambling disorder, but mainly only when psychiatric co-morbidities are present (73).

Moreover, it has been demonstrated that there is an in- crease in brain-derived neurotrophic factor serum levels in gamblers, compared to controls (74), and that the glutamatergic system is involved in neuronal alterations in gambling disorder. Therefore, drugs that modulate this neurotransmission system could be effective in treating the symptoms of craving and withdrawal (75).

\subsection{Conclusion}

Gamblers can be divided into two groups. The first comprises those with extreme gambling behavior which results in economic losses and debts that are so significant that a suicidal act, often aggravated by depression and hopelessness, appears to be the only solution. The second is gamblers in whom suicidal acts are precipitated by interpersonal and/or working challenges, in conjunction with an impulsivity personality trait (13).

The critical factors involved, specifically the tendency by gamblers to indulge in impulsive behavior and the impact of possible psychiatric co-morbidities, as well as social and cultural risk factors, need to be targeted in interventions to decrease gambling disorder and suicidality rates. The successful manipulation of these aspects would help to reduce gambling symptoms and suicidal behavior.

\section{Footnotes}

Authors' Contribution: All authors contributed to this review with equal efforts.

Conflict of Interest: The authors have no commercial or other interests which may have inappropriately influenced them when writing this paper.

Financial Disclosure: This manuscript was entirely funded by the authors. None of the pharmaceutical companies were informed of nor involved in the review process.

\section{References}

1. Oei TP, Gordon LM. Psychosocial factors related to gambling abstinence and relapse in members of gamblers anonymous.J Gambl Stud. 2008;24(1):91-105. doi:10.1007/s10899-007-9071-7. [PubMed: 17674163].

2. Rennert L, Denis C, Peer K, Lynch KG, Gelernter J, Kranzler HR. DSM5 gambling disorder: prevalence and characteristics in a substance use disorder sample. Exp Clin Psychopharmacol. 2014;22(1):50-6. doi: 10.1037/a0034518. [PubMed: 24490711].

3. Bullock SA, Potenza MN. Pathological Gambling: Neuropsychopharmacology and Treatment. Curr Psychopharmacol. 2012;1(1) doi: 10.2174/2211556011201010067. [PubMed: 24349964].

4. Bondolfi G, Osiek C, Ferrero F. Prevalence estimates of pathological gambling in Switzerland. Acta Psychiatr Scand. 2000;101(6):473-5. [PubMed: 10868471].

5. Romild U, Volberg R, Abbott M. The Swedish Longitudinal Gambling Study (Swelogs): design and methods of the epidemiological (EP-) track. Int J Methods Psychiatr Res. 2014;23(3):372-86. doi: 10.1002/mpr.1449. [PubMed: 24942902]. 
6. Wardle HMA, Spence S, Orford J, Volberg RA, Jotangia D. British Gambling prevalence survey 2010. London UK: The Gambling Commission; 2011.

7. Kastirke N, Rumpf HJ, John U, Bischof A, Meyer C. Demographic Risk Factors and Gambling Preference May Not Explain the High Prevalence of Gambling Problems Among the Population with Migration Background: Results from a German Nationwide Survey. I Gambl Stud. 2015;31(3):741-57. doi: 10.1007/s10899-014-9459-0. [PubMed: 24722950].

8. Villella C, Martinotti G, Di Nicola M, Cassano M, La Torre G, Gliubizzi MD, et al. Behavioural addictions in adolescents and young adults: results from a prevalence study. J Gambl Stud. 2011;27(2):203-14. doi: 10.1007/s10899-010-9206-0. [PubMed: 20559694].

9. Naoko T, Richard JR. Problem gambling in japan a social perspective. Electronic J Contemporary Japanese Studies. 2011;11.

10. Martinotti G, Andreoli S, Giametta E, Poli V, Bria P, Janiri L. The dimensional assessment of personality in pathologic and social gamblers: the role of novelty seeking and self-transcendence. Compr Psychiatry. 2006;47(5):350-6. doi: 10.1016/j.comppsych.2005.12.005. [PubMed: 16905396].

11. Janiri L, Martinotti G, Dario T, Schifano F, Bria P. The Gamblers' Temperament and Character Inventory (TCI) personality profile. Subst Use Misuse. 2007;42(6):975-84. doi: 10.1080/10826080701202445. [PubMed: 17613958].

12. Park S, Cho MJ, Jeon HJ, Lee HW, Bae JN, Park JI, et al. Prevalence, clinical correlations, comorbidities, and suicidal tendencies in pathological Korean gamblers: results from the Korean Epidemiologic Catchment Area Study. Soc Psychiatry Psychiatr Epidemiol. 2010;45(6):621-9. doi: 10.1007/s00127-009-0102-9. [PubMed: 19636479].

13. Wong PW, Cheung DY, Conner KR, Conwell Y, Yip PS. Gambling and completed suicide in Hong Kong: a review of coroner court files. Prim Care Companion J Clin Psychiatry. 2010;12(6) doi: 10.4088/PCC.09m00932blu. [PubMed: 21494351].

14. Hansen M, Rossow I. [Gambling and suicidal behaviour]. Tidsskr Nor Laegeforen. 2008;128(2):174-6. [PubMed: 18202728].

15. Hodgins DC, Mansley C, Thygesen K. Risk factors for suicide ideation and attempts among pathological gamblers. Am J Addict. 2006;15(4):303-10. doi: 10.1080/10550490600754366. [PubMed: 16867926].

16. Feigelman W, Gorman BS, Lesieur H. Examining the relationship between at-risk gambling and suicidality in a national representative sample of young adults. Suicide Life Threat Behav. 2006;36(4):396-408. doi: 10.1521/suli.2006.36.4.396. [PubMed: 16978094].

17. Moran J. Taking the final risk. Ment Health. 1969:21-2.

18. Frank ML, Lester D, Wexler A. Suicidal behavior among members of Gamblers Anonymous. J Gambl Stud. 1991;7(3):249-54. doi: 10.1007/BF01019876. [PubMed: 24243070].

19. Kausch O. Patterns of substance abuse among treatment-seeking pathological gamblers. J Subst Abuse Treat. 2003;25(4):263-70. [PubMed: 14693255].

20. Brodsky BS, Malone KM, Ellis SP, Dulit RA, Mann JJ. Characteristics of borderline personality disorder associated with suicidal behavior. Am J Psychiatry. 1997;154(12):1715-9. doi: 10.1176/ajp.154.12.1715. [PubMed: 9396951].

21. Blum K. Reward deficiency syndrome. In: Jg C, Er B, editors. Am Sci. ; 1996. pp. 132-45.

22. Petry NM. A comparison of treatment-seeking pathological gamblers based on preferred gambling activity. Addiction. 2003;98(5):645-55. [PubMed: 12751982].

23. Specker SM, Carlson GA, Edmonson KM, Johnson PE, Marcotte M. Psychopathology in pathological gamblers seeking treatment. J Gambl Stud. 1996;12(1):67-81. doi: 10.1007/BF01533190. [PubMed: 24233847].

24. Oliveira MP, Silveira DX, Silva MT. [Pathological gambling and its consequences for public health]. Rev Saude Publica. 2008;42(3):542-9. [PubMed: 18461253].

25. Newman SC, Thompson AH. The association between pathological gambling and attempted suicide: findings from a national survey in Canada. Can J Psychiatry. 2007;52(9):605-12. [PubMed:17953165].

26. Moghaddam JF, Yoon G, Dickerson DL, Kim SW, Westermeyer J. Suicidal ideation and suicide attempts in five groups with different severities of gambling: Findings from the National Epidemiologic Survey on Alcohol and Related Conditions. Am JAddict. 2015;24(4):292-8. doi: 10.1111/ajad.12197. [PubMed: 25808267].

27. Thon N, Preuss UW, Polzleitner A, Quantschnig B, Scholz H, Kuhberger A, et al. Prevalence of suicide attempts in pathological gamblers in a nationwide Austrian treatment sample. Gen Hosp Psychiatry. 2014;36(3):342-6. doi: 10.1016/j.genhosppsych.2014.01.012. [PubMed: 24630895]

28. Potenza MN, Fiellin DA, Heninger GR, Rounsaville BJ, Mazure CM Gambling: an addictive behavior with health and primary care implications. J Gen Intern Med. 2002;17(9):721-32. [PubMed: 12220370].

29. Seguin M, Boyer R, Lesage A, McGirr A, Suissa A, Tousignant M, et al. Suicide and gambling: psychopathology and treatment-seeking. Psychol Addict Behav. 2010;24(3):541-7. doi: 10.1037/a0019041. [PubMed: 20853941].

30. Bischof A, Meyer C, Bischof G, John U, Wurst FM, Thon N, et al. Suicidal events among pathological gamblers: the role of comorbidity of axis I and axis II disorders. Psychiatry Res. 2015;225(3):413-9. doi 10.1016/j.psychres.2014.11.074. [PubMed: 25537488].

31. Black DW, Coryell W, Crowe R, McCormick B, Shaw M, Allen J. Suicide Ideations, Suicide Attempts, and Completed Suicide in Persons with Pathological Gambling and Their First-Degree Relatives. Suicide Life Threat Behav. 2015;45(6):700-9. doi: 10.1111/sltb.12162. [PubMed: 25845522].

32. Martins SS, Tavares H, da Silva Lobo DS, Galetti AM, Gentil V Pathological gambling, gender, and risk-taking behaviors. Addict Behav. 2004;29(6):1231-5. doi: 10.1016/j.addbeh.2004.03.023. [PubMed: 15236828].

33. Manning V, Koh PK, Yang Y, Ng A, Guo S, Kandasami G, et al. Suicidal ideation and lifetime attempts in substance and gambling disorders. Psychiatry Res. 2015;225(3):706-9. doi: 10.1016/j.psychres.2014.11.011 [PubMed: 25555417].

34. Wong PW, Chan WS, Conwell Y, Conner KR, Yip PS. A psychological autopsy study of pathological gamblers who died by suicide. J Affect Disord. 2010;120(1-3):213-6. doi: 10.1016/j.jad.2009.04.001. [PubMed: 19395046].

35. Chen VC, Stewart R, Lee CT. Weekly lottery sales volume and suicide numbers: a time series analysis on national data from Taiwan. Soc Psy chiatry Psychiatr Epidemiol. 2012;47(7):1055-9. doi: 10.1007/s00127-0110410-8. [PubMed: 21681453].

36. Taber JI, McCormick RA, Ramirez LF. The prevalence and impact of major life stressors among pathological gamblers. Int J Addict. 1987;22(1):71-9. [PubMed:3557748].

37. Hall GW, Carriero NJ, Takushi RY, Montoya ID, Preston KL, Gorelick DA. Pathological gambling among cocaine-dependent outpatients. Am J Psychiatry. 2000;157(7):1127-33. doi: 10.1176/appi.ajp.157.7.1127. [PubMed: 10873922].

38. Spunt B, Lesieur H, Hunt D, Cahill L. Gambling among methadone patients. Int J Addict. 1995;30(8):929-62. [PubMed: 7558485].

39. MA S, TA K, BJ R. Cocaine abuse and pathological gambling. Am J of Addic. 1992:121-32.

40. Feigelman W, Wallisch LS, Lesieur HR. Problem gamblers, problem substance users, and dual-problem individuals: an epidemiological study. Am J Public Health. 1998;88(3):467-70. [PubMed: 9518986].

41. Lesieur HR, Blume SB, Zoppa RM. Alcoholism, drug abuse, and gambling. Alcohol Clin Exp Res. 1986;10(1):33-8. [PubMed: 3515989].

42. Lee KM, Guo S, Manning V, Thane K, Wong KE. Are the demographic and clinical features of pathological gamblers seeking treatment in Singapore changing? Singapore Med J. 2011;52(6):428-31. [PubMed: 21731995].

43. Malloy-Diniz LF, Neves FS, de Moraes PH, De Marco LA, Romano-Silva 
MA, Krebs MO, et al. The 5-HTTLPR polymorphism, impulsivity and suicide behavior in euthymic bipolar patients. J Affect Disord. 2011;133(12):221-6. doi: 10.1016/j.jad.2011.03.051. [PubMed: 21550122].

44. Di Nicola M, Tedeschi D, Mazza M, Martinotti G, Harnic D, Catalano V, et al. Behavioural addictions in bipolar disorder patients: role of impulsivity and personality dimensions. J Affect Disord. 2010;125(1-3):828. doi: 10.1016/j.jad.2009.12.016. [PubMed: 20083309].

45. Kawa I, Carter JD, Joyce PR, Doughty CJ, Frampton CM, Wells JE, et al. Gender differences in bipolar disorder: age of onset, course, comorbidity, and symptom presentation. Bipolar Disord. 2005;7(2):119-25. doi: 10.1111/j.1399-5618.2004.00180.x. [PubMed: 15762852].

46. Di Nicola M, De Risio L, Pettorruso M, Caselli G, De Crescenzo $\mathrm{F}$, Swierkosz-Lenart $\mathrm{K}$, et al. Bipolar disorder and gambling disorder comorbidity: current evidence and implications for pharmacological treatment. I Affect Disord. 2014;167:285-98. doi: 10.1016/j.jad.2014.06.023. [PubMed: 24999863].

47. Adida M, Jollant F, Clark L, Guillaume S, Goodwin GM, Azorin JM, et al. Lithium might be associated with better decision-making performance in euthymic bipolar patients. Eur Neuropsychopharmacol. 2015;25(6):788-97. doi: 10.1016/j.euroneuro.2015.03.003. [PubMed: 25840740].

48. Petry NM, Steinberg KL, Women's Problem Gambling Research C. Childhood maltreatment in male and female treatment-seeking pathological gamblers. Psychol Addict Behav. 2005;19(2):226-9. doi: 10.1037/0893-164X.19.2.226. [PubMed: 16011396].

49. Cunningham-Williams RM, Grucza RA, Cottler LB, Womack SB, Books SJ, Przybeck TR, et al. Prevalence and predictors of pathological gambling: results from the St. Louis personality, health and lifestyle (SLPHL) study. J Psychiatr Res. 2005;39(4):377-90. doi: 10.1016/j.jpsychires.2004.09.002. [PubMed:15804388].

50. Ledgerwood DM, Petry NM. Posttraumatic stress disorder symptoms in treatment-seeking pathological gamblers. J Trauma Stress. 2006;19(3):411-6. doi: 10.1002/jts.20123. [PubMed: 16789003].

51. Biddle D, Hawthorne G, Forbes D, Coman G. Problem gambling in Australian PTSD treatment-seeking veterans. J Trauma Stress. 2005;18(6):759-67. doi: 10.1002/jts.20084. [PubMed:16382440].

52. Kausch O, Rugle L, Rowland DY. Lifetime histories of trauma among pathological gamblers. Am J Addict. 2006;15(1):35-43. doi: 10.1080/10550490500419045. [PubMed: 16449091].

53. Najavits LM, Meyer T, Johnson KM, Korn D. Pathological gambling and posttraumatic stress disorder: a study of the co-morbidity versus each alone. J Gambl Stud. 2011;27(4):663-83. doi: 10.1007/s10899-0109230-0. [PubMed: 21191636].

54. Shaffer HJ, Korn DA. Gambling and related mental disorders: a public health analysis. Annu Rev Public Health. 2002;23:171-212. doi:10.1146/annurev.publhealth.23.100901.140532. [PubMed: 11910060].

55. Haaland VO, Landro NI. Decision making as measured with the Iowa Gambling Task in patients with borderline personality disorder. J Int Neuropsychol Soc. 2007;13(4):699-703. doi:10.1017/S1355617707070890. [PubMed: 17521489].

56. Barrault S, Varescon I. [Psychopathology in online pathological gamblers: a preliminary study]. Encephale. 2012;38(2):156-63. doi: 10.1016/j.encep.2011.01.009. [PubMed: 22516274].

57. Petry NM, Kiluk BD. Suicidal ideation and suicide attempts in treatment-seeking pathological gamblers. J Nerv Ment Dis. 2002;190(7):462-9. doi: 10.1097/01.NMD.0000022447.27689.96. [PubMed: 12142848].

58. Morasco BJ, Pietrzak RH, Blanco C, Grant BF, Hasin D, Petry NM. Health problems and medical utilization associated with gambling disorders: results from the National Epidemiologic Survey on Alcohol and Related Conditions. Psychosom Med. 2006;68(6):976-84. doi: 10.1097/01.psy.0000238466.76172.cd. [PubMed: 17132843].

59. Saarni SI, Suvisaari J, Sintonen H, Pirkola S, Koskinen S, Aromaa A, et al. Impact of psychiatric disorders on health-related quality of life: general population survey. Br J Psychiatry. 2007;190:326-32. doi: 10.1192/bjp.bp.106.025106. [PubMed: 17401039].

60. Merikangas KR, Ames M, Cui L, Stang PE, Ustun TB, Von Korff M, et al. The impact of comorbidity of mental and physical conditions on role disability in the US adult household population. Arch Gen Psychiatry. 2007;64(10):1180-8. doi:10.1001/archpsyc.64.10.1180. [PubMed: 17909130].

61. Chou KL, Afifi TO. Disordered (pathologic or problem) gambling and axis I psychiatric disorders: results from the National Epidemiologic Survey on Alcohol and Related Conditions. Am J Epidemiol. 2011;173(11):1289-97. doi: 10.1093/aje/kwr017. [PubMed: 21467151].

62. Lawrence PR, Shoshana EF, Mona R. The long-term stability of early maladaptive schemas. Cog Ther and Res. 2006:515-29.

63. Glenn W, Caroline M, Vartouhi O. Psychometric properties of the long and short versions of the young schema questionnaire: Core beliefs among bulimic and comparison women. Cog Ther and Res. 2001:13747.

64. Cockram DM, Drummond PD, Lee CW. Role and treatment of early maladaptive schemas in Vietnam Veterans with PTSD. Clin Psychol Psychother. 2010;17(3):165-82. doi: 10.1002/cpp.690. [PubMed: 20486158].

65. Ball SA, Cecero JJ. Addicted patients with personality disorders: traits, schemas, and presenting problems. J Pers Disord. 2001;15(1):72-83. [PubMed: 11236816].

66. Giesen-Bloo J, van Dyck R, Spinhoven P, van Tilburg W, Dirksen $C$, van Asselt $T$, et al. Outpatient psychotherapy for borderline personality disorder: randomized trial of schema-focused therapy vs transference-focused psychotherapy. Arch Gen Psychiatry. 2006;63(6):649-58. doi: 10.1001/archpsyc.63.6.649. [PubMed: 16754838].

67. Martinotti G, Nicola MD, Reina D, Andreoli S, Foca F, Cunniff A, et al. Alcohol protracted withdrawal syndrome: the role of anhedonia. Subst Use Misuse. 2008;43(3-4):271-84. doi: 10.1080/10826080701202429. [PubMed: 18365930].

68. Lawrence AJ, Luty J, Bogdan NA, Sahakian BJ, Clark L. Impulsivity and response inhibition in alcohol dependence and problem gambling. Psychopharmacology (Berl). 2009;207(1):163-72. doi: 10.1007/s00213009-1645-x. [PubMed: 19727677].

69. Yen S, Shea MT, Sanislow CA, Skodol AE, Grilo CM, Edelen MO, et al. Personality traits as prospective predictors of suicide attempts. Acta Psychiatr Scand. 2009;120(3):222-9. doi: 10.1111/j.1600-0447.2009.01366.x. [PubMed: 19298413].

70. Grall-Bronnec M, Wainstein L, Feuillet F, Bouju G, Rocher B, Venisse $\mathrm{JL}$, et al. Clinical profiles as a function of level and type of impulsivity in a sample group of at-risk and pathological gamblers seeking treatment. J Gambl Stud. 2012;28(2):239-52. doi: 10.1007/s10899-011-9258-9. [PubMed: 21698341].

71. Klonsky ED, May A. Rethinking impulsivity in suicide. Suicide Life Threat Behav. 2010;40(6):612-9. doi: 10.1521/suli.2010.40.6.612. [PubMed: 21198330].

72. Miller JFK, Lynam D, Leukefeld C. A test of the four-factor model of impulsivity related traits. Pers Individ Dif. 2003:1403-18.

73. Lupi M, Martinotti G, Acciavatti T, Pettorruso M, Brunetti M, Santacroce R, et al. Pharmacological treatments in gambling disorder: a qualitative review. Biomed Res Int. 2014;2014:537306. doi: 10.1155/2014/537306. [PubMed: 24955359].

74. Angelucci F, Martinotti G, Gelfo F, Righino E, Conte G, Caltagirone $\mathrm{C}$, et al. Enhanced BDNF serum levels in patients with severe pathological gambling. Addict Biol. 2013;18(4):749-51. doi: 10.1111/j.13691600.2011.00411.x. [PubMed: 22044515].

75. Pettorruso M, De Risio L, Martinotti G, Di Nicola M, Ruggeri F, Conte $\mathrm{G}$, et al. Targeting the glutamatergic system to treat pathological gambling: current evidence and future perspectives. Biomed Res Int. 2014;2014:109786. doi: 10.1155/2014/109786. [PubMed: 25013755]. 